Six species, namely the squirrel monkey, capuchin, ferret, dog, hedgehog and rabbit, excreted only three metabolites. The two herbivorous New World monkeys excreted phenyl glucuronide, quinol glucuronide and phenyl sulphate, and, at the dose of phenol used, glucuronic acid conjugation appeared to be more effective than sulphate conjugation in these two species. The other four species, however, excreted phenyl sulphate, quinol sulphate and phenyl glucuronide, and these species varied according to the extent to which they utilized the two conjugation mechanisms and in the extent of oxidation of phenol to quinol.

Four species, the rhesus monkey, cat, fruit bat and chicken, excreted only two metabolites, and one species, the pig, only one. The rhesus monkey, fruit bat and hen excreted phenyl sulphate and phenyl glucuronide, but no quinol conjugates. The cat appeared to excrete only phenyl sulphate and quinol sulphate, whereas the pig appeared to excrete only phenyl glucuronide.

The apparent inability of the cat to utilize the glucuronic acid mechanism and the pig the sulphate mechanism for the conjugation of phenol was therefore investigated in greater detail. It was found that these mechanisms were not entirely absent as far as phenol is concerned, since they were found at a very low level. The pig given $\left[{ }^{14} \mathrm{C}\right]$ phenol orally or intraperitoneally excreted more than $90 \%$ of the $24 \mathrm{~h}{ }^{14} \mathrm{C}$ excretion as phenyl glucuronide, but small amounts of phenyl sulphate $(0.2-8.3 \%)$ were also detected. Similarly, in the cat, although phenyl sulphate and quinol sulphate accounted for over $90 \%$ of an oral or injected dose of $\left[{ }^{14} \mathrm{C}\right]$ phenol, small amounts $(0.1-$ $2.0 \%$ of the $24 \mathrm{~h}{ }^{14} \mathrm{C}$ excretion) of phenyl glucuronide were also found in the urine.

This work was supported by a grant from the Medical Research Council.

Adamson, R. H., Bridges, J. W., Evans, M. E. \& Williams, R. T. (1970) Biochem. J. 116, 437-443

Bridges, J. W., French, M. R., Smith, R. L. \& Williams, R. T. (1970) Biochem. J. 118, 47-51

Dring, L. G., Smith, R. L. \& Williams, R. T. (1970) Biochem. J. 116, 425-435

James, M., Smith, R. L. \& Williams, R. T. (1971) Biochem. J. 124, 15P-16P

\section{Dehydrogenation of DL-Methylphenylcarbinol in the Rat}

By R. P. Hopkins, P. A. Borge and P. Callaghan (Department of Biochemistry, St. Thomas's Hospital Medical School, London S.E.1, U.K.)

Although methylphenylcarbinol ( $\alpha$-hydroxyethylbenzene) gives rise to methylphenylcarbinol glucuronide, hippuric acid and mandelic acid after admin- istration to rabbits (Smith et al., 1954a), the dehydrogenation of the carbinol to acetophenone does not seem to have been reported. Reduction of acetophenone, however, does occur in the rabbit and the dog (Smith et al., 1954b; Leibman, 1971; Sundvik, 1886). The present investigation was undertaken to determine whether methylphenylcarbinol is oxidized in a manner similar to other carbinols such as indan1-ol (Billings et al., 1971) and acenaphthen-1-ol (Simmons et al., 1971), which gave rise to the corresponding ketones.

Ether extracts of the urine from rats injected subcutaneously with DL-methylphenylcarbinol were examined by t.l.c. and g.l.c. Acetophenone and the free carbinol were detected. The extent of the conversion into acetophenone was estimated from g.l.c. traces at $0.15 \%$ of the dose, which compares well with the conversion of indan-1-ol into indan-1-one (Billings et al., 1970).

The oxidation of methylphenylcarbinol by rat liver preparations was also examined. The compound was incubated with a microsomal preparation and with a $100000 \mathrm{~g}$ supernatant preparation in the presence of $\mathrm{NAD}^{+}$or $\mathrm{NADP}^{+}$at $\mathrm{pH} 7.4$ and $37^{\circ} \mathrm{C}$. Ether extracts of these systems were examined by t.l.c. and g.l.c. and were found to contain acetophenone in all cases. The rate of oxidation of methylphenylcarbinol was followed in similar systems by measuring the increase in $E_{340}$.

These experiments showed that both the microsomal system and the cytosol are active with NAD $^{+}$ and NADP ${ }^{+}$, and that $\mathrm{NAD}^{+}$is the preferred cofactor for both systems. These cofactor requirements for the microsomal oxidation of methylphenylcarbinol are similar to those for the oxidation of acenaphthen-1-ol and cis- and trans-acenaphthene1,2-diol (Simmons et al., 1971; Drummond, 1971). The oxidation of these latter compounds by the cytosol, however, has a specific requirement for NADP ${ }^{+}$. The results of this investigation also indicate that the activity of the rat liver cytosol differs from that of a similar bovine liver preparation that Billings $e t$ al. (1971) showed to have no activity towards methylphenylcarbinol.

A more detailed study of the rat liver supernatant preparation is being conducted.

Billings, R. E., Sullivan, H. R. \& McMahon, R. E. (1970) Biochemistry 9, 1256

Billings, R. E., Sullivan, H. R. \& McMahon, R. E. (1971) J. Biol. Chem. 246, 3512

Drummond, E. C. (1971) Ph.D. Thesis, University of London

Leibman, K. C. (1971) Xenobiotica 1, 97

Simmons, C. J., Hopkins, R. P. \& Callaghan, P. (1971) Biochem. J. 124, 26P

Smith, J. N., Smithies, R. H. \& Williams, R. T. (1954a) Biochem. J. 56, 320 
Smith, J. N., Smithies, R. H. \& Williams, R. T. (1954b)

Biochem. J. 57, 74

Sundvik, E. (1886) Jahresber. Thierchem. 16, 76

\section{Liver L-Serine-Pyruvate Aminotransferase Activity in Different Animal Species}

By E. V. Rowsell, A. H. Al-Tai and J. A. Carnie (Department of Biochemistry, University of Manchester Institute of Science and Technology, Manchester M60 1QD, U.K.) and KATHLEEN V. RowSELL (Department of Medical Biochemistry, University of Manchester, Manchester M13 9PL, U.K.)

In a comparative survey for liver serine dehydratase, covering the pig, sheep, rabbit, guinea pig, rat, mouse and common shrew, activity was found to increase consistently with decreasing body size-with increasing basal metabolism (Rowsell et al., 1965). From recent assays we can report that the body size relationship still holds when we include values for cat and dog liver. With amphibian liver (from common frog, green tree frog, natterjack toad), however, we find no measurable activity.

The distribution pattern for L-serine-pyruvate aminotransferase activity is altogether different. Assays were made on homogenates of fresh liver by measuring hydroxypyruvate formation with Dglycerate dehydrogenase (Rowsell et al., 1969). The results obtained, expressed as $\mu \mathrm{mol}$ of hydroxypyru$v a t e / h$ per $g$ of tissue, as means \pm S.D. (nos. of animals), were as follows: mouse, $4.66 \pm 0.86$ (5); blackhooded rat, $1.59 \pm 0.27$ (10); Sprague-Dawley rat, $4.45 \pm 0.77$ (9); Wistar rat, $3.30 \pm 0.47$ (7); guinea pig, $0.53 \pm 0.19$ (3); rabbit, $24.8 \pm 4.5$ (12); sheep, $1.07 \pm 0.20$ (4); pig, $1.42 \pm 0.44$ (4); cat, $94 \pm 32$ (6); dog, $126 \pm 49$ (14); common frog, $54 \pm 10$ (5); common toad, 51.5 and 46.3. The most notable feature is the outstandingly high activity in the carnivorous species.

The reverse reaction, with hydroxypyruvate and L-alanine as substrates, was assayed, by measuring serine formation with ninhydrin after separation by paper chromatography (Kay et al., 1956). Dog and frog liver activities were 2-3-fold greater than with L-serine and pyruvate as substrates; and we note that Sallach's (1956) original studies on serine formation by transamination employed a dog liver enzyme. Even so, it is difficult to accept that the function of this enzyme is to form L-serine: the flesh eater, presumably, derives an abundant supply of amino acids from its food; it seems unlikely it would be especially well equipped for their synthesis. We assume, rather, that the enzyme operates, at least in the carnivore, to convert L-serine into hydroxypyruvate as the first step towards glucose formation via D-glycerate.
Moreover for rat liver there is evidence that $\mathrm{L}$-serine is converted into glucose without being liberated as pyruvate, from perfusion studies; testing the effects of quinolinate, a potent inhibitor of phosphoenolpyruvate carboxykinase (Lardy et al., 1969). The authors conclude that L-serine-pyruvate aminotransferase, rather than L-serine dehydratase, is the enzyme initiating gluconeogenesis from L-serine. Our comparative findings are consistent with that suggestion.

Kay, R. E., Harris, D. C. \& Entenman, C. (1956) Arch. Biochem. Biophys. 63, 14

Lardy, H. A., Veneziale, C. M. \& Gabrielli, F. (1969) FEBS Symp. 19, 55

Rowsell, E. V., Carnie, J. A. \& Wahbi, S. D. (1965) Biochem. J. 96, 13P

Rowsell, E. V., Snell, K., Carnie, J. A. \& Al-Tai, A. H. (1969) Biochem. J. 115, 1071

Sallach, H. J. (1956) J. Biol. Chem. 223, 1101

\section{Activities of Phosphopyruvate Carboxylase and Citrate Synthase in Rat and Cow Liver after Glucocorticoid Administration}

By R. J. Heitzman, I. D. Herriman and C. B. MALlinson (Agricultural Research Council Institute for Research on Animal Diseases, Compton, Newbury, Berks., U.K.)

The administration of a glucocorticoid to rats increases hepatic gluconeogenesis and ketogenesis. However, Baird \& Heitzman (1971) have shown that glucocorticoids are antiketogenic and possibly do not increase gluconeogenesis in bovine liver.

In investigations of the reasons for this difference, the metabolic role of oxaloacetate has been an important consideration. Oxaloacetate is at a key branching point: it can be converted into phosphoenolpyruvate via the phosphopyruvate carboxylase reaction or into citrate through the citrate synthase reaction. The activities of these enzymes are important, since they could affect the fate of oxaloacetate and thus gluconeogenesis and ketogenesis. The subcellular distribution of these enzymes is also important; in rat liver phosphopyruvate carboxylase is almost exclusively located in the cytoplasm whereas citrate synthase is a mitochondrial enzyme. The enzymes distribute much more evenly between cytoplasm and mitochondria in bovine liver cells.

The administration of $10 \mathrm{mg}$ of dexamethasone 21 -isonicotinate to healthy cows resulted, $48 \mathrm{~h}$ later, in a significant decrease of the hepatic phosphopyruvate carboxylase activity in the cytoplasm to $36 \%$ of the control value with no effect on the activity of the particulate enzyme. The citrate synthase activity in bovine liver was increased to $180 \%$ of the control value in the particulate fraction and to $187 \%$ in the 